Article

\title{
Everyday Use of the City Cemetery: A Study of Environmental Qualities and Perceived Restorativeness in a Scottish Context
}

\author{
Ka Yan Lai ${ }^{1, *}$, Iain Scott ${ }^{2} \mathbb{1}$ and Ziwen Sun ${ }^{2}$ \\ 1 Department of Urban Planning and Design, Faculty of Architecture, The University of Hong Kong, \\ Pok Fu Lam, Hong Kong \\ 2 Edinburgh School of Architecture and Landscape Architecture, Edinburgh College of Art, \\ University of Edinburgh, Scotland EH1 1JZ, UK \\ * Correspondence: laikyy@hku.hk
}

Received: 17 June 2019; Accepted: 12 July 2019; Published: 16 July 2019

\begin{abstract}
As the number of historical urban cemeteries where interment is no longer available continues to grow, the everyday use and restorative benefit of these spaces (beyond commemoration and remembrance) is worthy of further exploration. This study primarily investigates the everyday use of two historical urban cemeteries in Edinburgh through behavioural observation $(N=185)$. We also explore further the relationships between cemetery qualities and perceived restorativeness through an interviewer-administered survey $(N=134)$ and face-to-face interviews $(N=24)$ at the sites. The survey findings showed that usage and aesthetics in the cemeteries were both significantly and positively associated with various restorative qualities including 'being away', 'fascination' and 'compatibility'. The data provided from the interviews and behavioural observations complement the survey findings that the everyday use of urban cemeteries (i.e., using them as an alternative route for pedestrian journeys or simply walking the dog) could facilitate users' mental restorative process. After controlling for sociodemographic characteristics, provision of facilities (e.g., benches and toilets) was found to have no significant association with any restorative qualities. Using a mixed method approach, this study provides a novel understanding of how the urban population uses, and perceives, old urban cemeteries in contemporary Scotland.
\end{abstract}

Keywords: cemetery; everyday use; perceived restorativeness; Scottish context

\section{Introduction}

Urban greenspace has generally been found to encompass various environmental qualities, which help to facilitate people's perceived restorativeness [1,2], restoring depleted psychological resources [3,4]. Previous research has generally focused on parks, rather than informal urban greenspace [5]. In considering the dimension of proximity, access to formal urban greenspace in a person's neighbourhood could be an obstacle for urban populations [6]. Subsequently, informal urban greenspace might be more important for everyday use and become an increasingly significant research topic, such as brownfield land, railway verges [7], vacant lots [8], golf courses [9], zoos [10], and cemeteries [11]. With the growing number of urban cemeteries [12] and the potential integration of everyday use into this park-like environment [12,13], this study is divided into two parts: 1) Investigating the everyday use of historical urban cemeteries in a Scottish context; 2) exploring the relationships between the environmental qualities of these places, and people's perceived restorativeness. 


\subsection{The Everyday Use of Historical Urban Cemeteries}

As shown in the National Land Use Nomenclature, cemeteries in the UK are categorised as 'utilities and infrastructure', suggesting a place for 'storage and disposal of human remains' [14] (p. 38). However, interment is often no longer available in historical urban cemeteries. Though burial plot recycling has been proposed to address cemetery overcrowding, previous studies have shown that urban cemeteries, a cultural institution filled with many beliefs and values, are used by local residents in many different ways, displaying the various roles these spaces play in the everyday life of the city $[13,15]$. Cemeteries are habitats to a rich variety of birds, and generate a series of different human behaviours in response to activities and other environmental characteristics [16]. The use of cemeteries by tourists has also been studied, exploring the economic and educational potential of these places [17]. Swensen et al. [18] found that Finnish cemeteries could also be regarded as a route of local pedestrian travel, indicating that walking for exercise was the most common everyday use in the cemetery, followed by cycling, walking the dog, walking with babies in prams, and contemplation. Tângari [19] highlighted that cemeteries could be categorised as urban open space that supports interment as well as other activities related to commerce, recreation, or sports. Recently, cemeteries as a peaceful place in the city were found to be 'a park-like environment' for restoration, in another qualitative study based in Norway, where four restorative elements including 'fascination', 'being away', 'compatibility', and 'coherence' were discussed [11] (p. 109-110). These studies, primarily being conducted in the Scandinavian region, displayed further potential uses of cemeteries in the city, rather than solely being used for the purpose of human interment separated from people's daily living [20-22]. In order to address the inadequate relevant evidence in the UK, this is the first study to investigate the everyday use of the historical urban cemetery in a Scottish context through behavioural observation.

\subsection{Environmental Qualities and Perceived Restorativeness in the Cemetery}

Attention restoration theory (ART) highlights the recovery of an individual's capacity to concentrate on a specific task with minimal cognitive effort [23]. Directed attention, the principal concept of the theory, helps to facilitate people's mental effectiveness in their daily lives [24]. A natural environment is believed to enable a more complete restorative experience by effortlessly restoring the capacity for a person's directed attention [24,25]. Based on the theory, perceived restorativeness can be divided into four sub-dimensions consisting of 'being away', 'fascination', 'compatibility', and 'coherence' [3]. Being away represents physically being away in a novel setting or having a psychological experience of escape from a person's everyday routine $[4,26]$. Fascination refers to holding one's involuntary attention through interesting stimulations, allowing directed attention to rest. Compatibility emphasises consistency between a person's purpose and experienced environmental features [24]. The discussion of this quality is usually about the relationship between the 'demands' of a person and the 'supply' of an environment. Coherence was originally included in another component of 'extent' [27], and subsequently divided into two factors of connectedness and scope [28]. With reference to the discussions of coherence by Hauru et al. [27] and Pals et al. [28], in this study we define coherence as the perception of an environment being ordered and having sufficient scope for preferred physical and imaginative activities. As raised by Kaplan [24], a place with sufficient scope 'provide(s) enough to see, experience, and think about' in order to engage a person's mind (p. 173). An environment with these four characteristics can be regarded as having restorative potential.

Restorativeness emphasises the involuntary recovery from mental fatigue [29]. With the growing urban population and the need for good mental health in coping with pressurised modern lifestyles [30], improving restorativeness in contemporary cities becomes an increasingly significant research topic. Previous empirical findings generally show that urban greenspace can provide a liveable, peaceful, and walkable environment that encourages perceived restorativeness [31]. In terms of usage, running in parks or outside towns was found to have a positive association with perceived restorativeness [32]. Walking was also found to have a positive impact upon mental health [33]. With regard to aesthetics, the perceptions of greenspace qualities including perceived greenness, perceived birds, perceived butterflies, 
and perceived plants and trees were positively associated with perceived restorativeness [2,23]. For facilities, the aspect of refuge, representing the presence of benches, tables, and play equipment of small public urban greenspace was associated with compatibility and coherence of perceived restorativeness [34]. Perceived safety, which may affect the use of public parks, was also beneficially associated with perceived restorativeness [35]. Compared with physical aspects, population perception towards urban greenspace is more crucial to affect visitorship and to inform future greenspace planning [36].

However, many publications relating to the perceptions of greenspace features and perceived restorativeness have been limited to studying formal greenspace such as public parks and gardens. In order to address the common negligence of the role of informal greenspace in the city, this study further explores the relationships between the environmental qualities of historical urban cemeteries and people's perceived restorativeness through a survey and interviews at sites. Previous publications generally adopted a qualitative approach, mostly interviews, to investigate an individual's perceptions towards cemeteries. This is the first study that has employed a mixed method approach to explore the associations between environmental qualities of historical urban cemeteries and people's perceived restorativeness in contemporary Scotland. Based on the literature review and the subsequent factor analysis as demonstrated in the following section, we proposed four hypotheses $(\mathrm{H})$ as shown below:

H1. Usage of the study's cemeteries is positively associated with perceived restorativeness.

H2. Aesthetics of the study's cemeteries is positively associated with perceived restorativeness.

H3. Presence of facilities in the study's cemeteries is positively associated with perceived restorativeness.

H4. Safety of the study's cemeteries is positively associated with perceived restorativeness.

\section{Methods}

\subsection{Study Design and Participants}

Figure 1 presents the study procedures in relation to the research questions. The methods of behavioural observation, an interviewer-conducted survey, and face-to-face interview at the sites were conducted from March to April 2018 in two cemetery sites in the City of Edinburgh, Scotland, UK. At each site, data collection was conducted for five days, of which three were weekdays and two were weekend days. Time used for data collection included 7 hours each day (09.00-12.00 and 13.00-17.00). One specific observatory point (Figures 2 and 3) was chosen by the researcher at each site based on the amount of users passing by, so as to increase the potential of data collection. Users' behaviours were firstly recorded (details are shown below). They were then invited to answer the survey questions. Some of them were further invited to participate in an interview (criteria for interviews and other details are shown below). Although some users were found more than once at the study sites during the survey period, each of them was invited only once for the interview. All eligible participants were aged 18 or above and could answer the survey questions independently. When the researcher encountered more than one person walking together, all of them were invited to participate in the study. However, they usually preferred that only one of them answered the questionnaire. Ethical approval has been granted by the University of Edinburgh. 


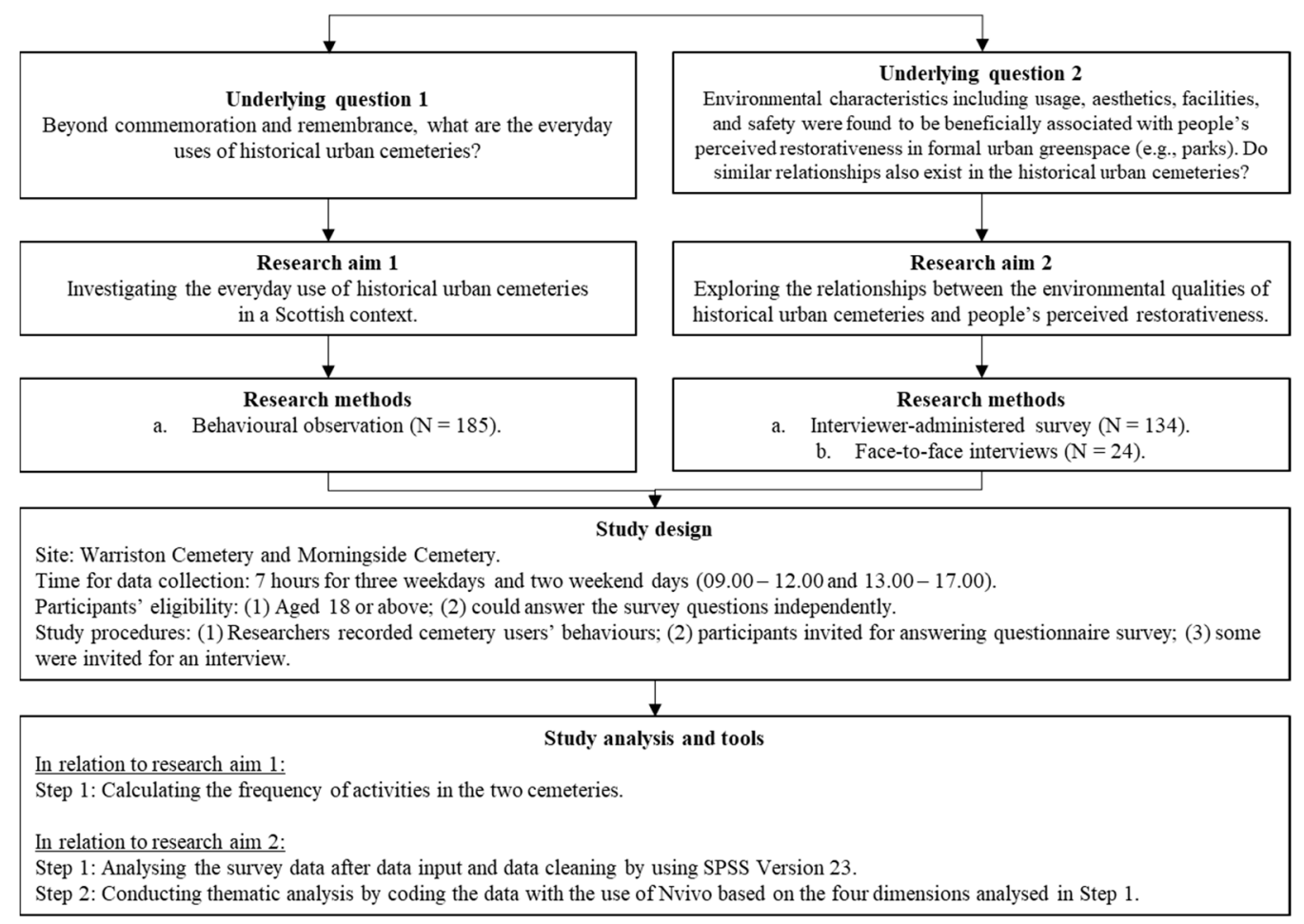

Figure 1. Research procedures in relation to the research questions.

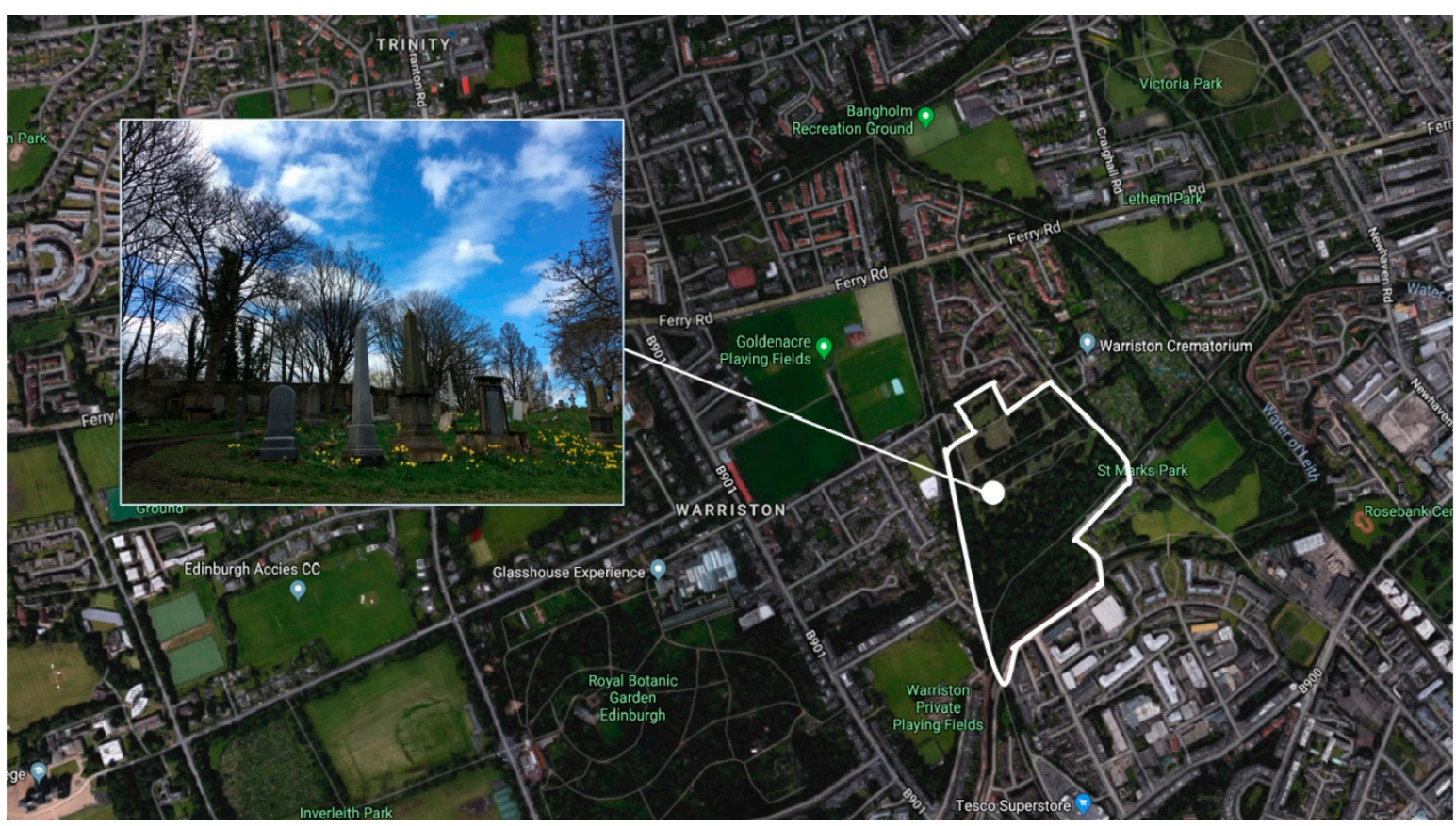

Figure 2. Map and image of the Warriston Cemetery in Edinburgh (the map was retrieved from www.google.no/maps/). The white spot indicates the location where data collection was conducted, and the white line indicates the boundary of the Warriston Cemetery. 


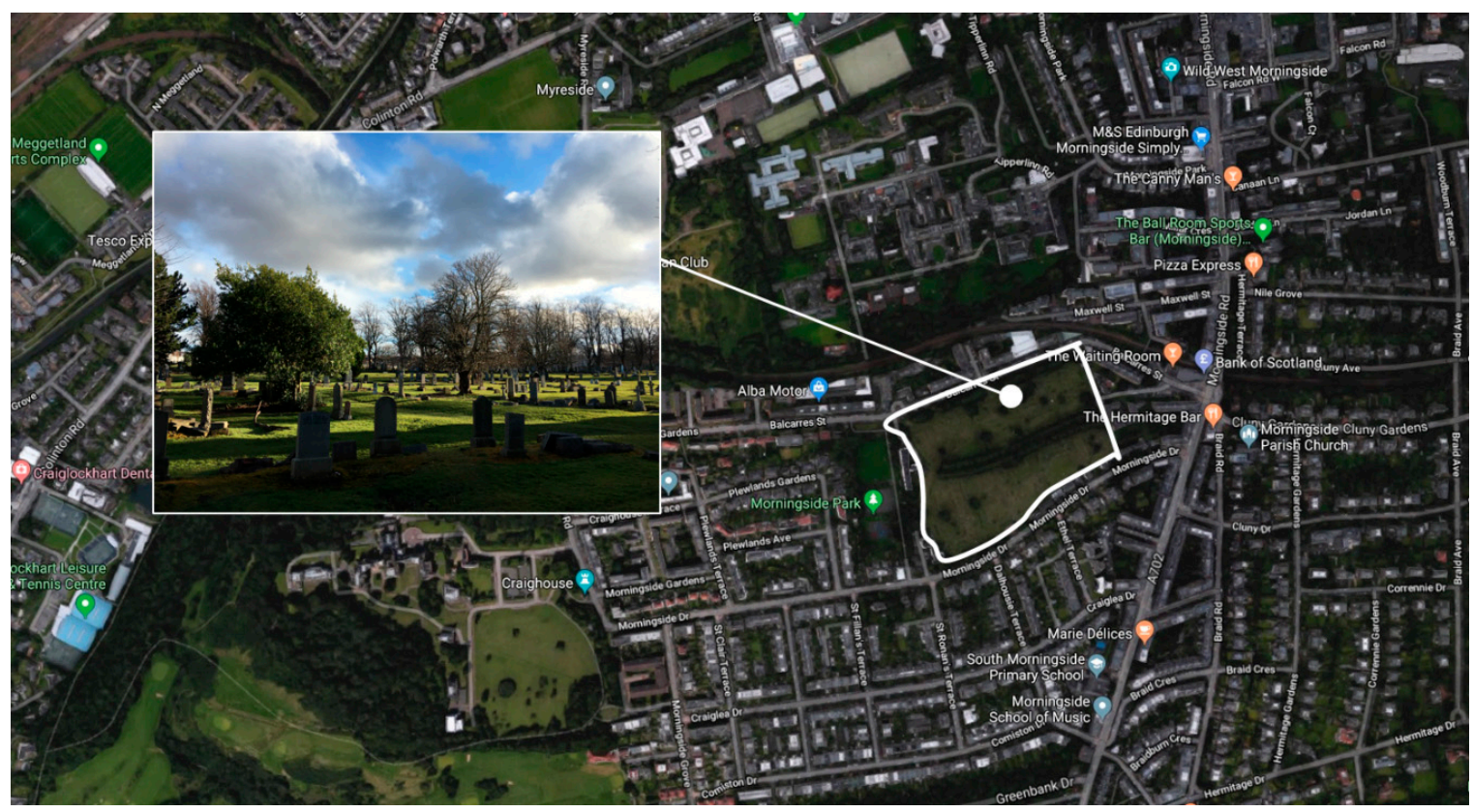

Figure 3. Map and image of the Morningside Cemetery in Edinburgh (the map was retrieved from www.google.no/maps/). The white spot indicates the location where data collection was conducted, and the white line indicates the boundary of the Morningside Cemetery.

\subsection{Study Sites}

Edinburgh is the capital city of Scotland. Its population reached over 500,000 in 2017 [37]. With the growing population and rapid expansion of the city from the early 19th century, many private cemeteries were instituted to address the growing problem of inadequate space for the interment of human remains. Many of these historical cemeteries are now under the control of the City Council, but no longer available for burial use due to being full. Two historical cemeteries, the Warriston Cemetery (Figure 2) and the Morningside Cemetery (Figure 3) in the north and south of the city, and which opened in 1843 and 1878, respectively, were selected for this study. The Warriston Cemetery $(88,815.72$ square meters) is surrounded by residential land use. To the south of the Morningside Cemetery (55,099.82 square meters), a large number of residential plots exist, while land to the northeast is mostly occupied by commercial businesses. In order to select the two study sites, all of the cemeteries in the list of cemeteries in Edinburgh [38] were initially visited by the main researcher. From this initial observation, it was clear that the Warriston and Morningside cemeteries were two of the most intensively used of the various cemeteries visited, resulting in their selection as study sites.

\subsection{Behavioural Observations}

\section{Data Collection}

Behavioural observations are useful to provide quantitative data to determine the levels of behaviours, and frequency is one of the most common features to observe. Users' behaviours were recorded on a record sheet at each site in a systematic way. The record sheet mainly contained two elements comprised of gender and activities. For example, 'dog' was used to represent the behaviour of 'dog walking'. As this study intended to explore the overall use of cemeteries, recurring users were coded as many times as they appeared in the study area. If a group of users appeared in the study area at the same time, photos were first taken before their behaviours were recorded. 


\subsection{Interviewer-Administered On-Site Survey}

\subsubsection{Measures}

The Neighbourhood Open Space Scale (13 items) was used to measure the independent variables of environmental qualities in the cemeteries [39]. The scale was rated by using a 5-point Likert scale ranging from '(1) strongly disagree' to '(5) strongly agree'. The term 'neighbourhood open space' was changed to 'cemeteries' in the questionnaire. Though the scale was used to measure the perceived neighbourhood open space in the UK before, principal component analysis was conducted to divide the 13 items into various dimensions based on the specific cemetery context. Items with a factor loading lower than 0.50 were excluded. After exclusion, the Kaiser-Meyer-Olkin (KMO) of the scale was $0.636(p=0.000)$, indicating an acceptable level of sampling adequacy. Varimax rotation was adopted. Only 10 items remained after the factor analysis (Table A1). The four dimensions were safety (4 items, e.g., the cemetery is free from crime), usage (4 items, e.g., the paths to the cemeteries are enjoyable to walk through), facilities (single item, i.e., there are good facilities in the cemetery), and aesthetics (single item, i.e., trees and plants in the cemetery are attractive). The former two had a Cronbach's alpha $(\alpha)$ score higher than 0.50 , indicating an acceptable level of internal consistency. A higher mean score for each dimension indicated a higher perception of a particular quality in the cemeteries.

The 16-item Perceived Restorativeness Scale (16-item PRS scale), commonly applied in previous studies $[23,34,40]$ was used to measure perceived restorativeness [4] as the outcome variable of this study. The scale was rated by using a 7-point Likert scale ranging from '(0) not at all' to '(6) very much'. It was used in the UK previously with validated reliability [23]. The mean score of the 16 items was calculated to form a 16-item PRS scale. Mean scores of the four dimensions as discussed above were also reported for further studies. As the items of coherence imply negative meanings, scores for its items were reversed before calculation. A higher score indicated a higher level of restorative quality. Similar to the previous study (16-item PRS scale: $\alpha=0.90$; being away: $\alpha=0.85$; fascination: $\alpha=0.94$; compatibility: $\alpha=0.92)$ [23], the Cronbach's alpha scores of the 16-item PRS scale $(\alpha=0.891)$, being away $(\alpha=0.832)$, fascination $(\alpha=0.860)$, and compatibility $(\alpha=0.869)$ were at acceptable levels in this study. However, compared with the previous analysis conducted (coherence: $\alpha=0.62$ ) [23], the dimension of coherence $(\alpha=0.483)$ had a relatively low Cronbach's alpha score in this study, indicating a relatively low level of internal consistency. As it nearly reaches 0.50 as a basic acceptable level, coherence was also included to examine its associations with different environmental qualities for further analysis and discussion.

Sociodemographic characteristics including age, gender, marital status, education level, and working status were reported. Interviewees were also asked if they had any physical disability. Physical disability is defined as perceived difficulty in mobility in this study [41].

As the survey data were collected from two sites, the Warriston Cemetery and the Morningside Cemetery were coded as 1 and 0 respectively to indicate the uniqueness of the two cemeteries.

\subsubsection{Data Analysis}

The study firstly used SPSS Version 23 to analyse the survey data. All survey data collected in the two study sites were combined for analysis. Missing data were replaced by a mean value, despite the low missing rate. Descriptive analysis was initially conducted to present the number of samples at each site and participants' sociodemographic characteristics. Bivariate analysis was then conducted to explore the correlations between environmental qualities and outcome variables (16-item PRS scale and other sub-dimensions of perceived restorativeness). Outcome variables in the bivariate analysis at significant levels were further analysed in the regression analysis. Multiple linear regression was conducted to explore the effect of environmental qualities on the 16-item PRS scale and other dimensions of perceived restorativeness, after controlling for sociodemographic characteristics and site selections. 


\subsection{Face-to-Face On-Site Interviews}

\subsubsection{Interviews}

A total of 24 interviews were conducted at the two study sites, where 12 interviews (6 male and 6 female) were conducted at each site. On average, one to two interviews were conducted per day. Gender was controlled so as to ensure gender balance in the number of participants. In order to understand how users perceive the environment through a more comprehensive approach, and to help interpret the survey data, each interview began with two core questions- 'Why are you here today?' and 'What do you think about the environment in this place?' [42]. The following questions were dependent on the interviewees' answers. For example, when the respondents noted that they liked the gravestones in the cemetery without any explanations, they were further asked about the reasons behind the answers given. Each interview took approximately 10 to 15 minutes. The main points of the discourse were recorded on a table (containing gender, site, questions, and response) by the researcher during the interviews, including direct quotations. Some incomplete data were further expanded [42] as a complete sentence from the interviewees' perspectives on the same day of data collection when the main researcher still kept fresh memory with regard to the discourse. This explains why the following interview data look verbatim.

\subsubsection{Data Analysis}

Using Nvivo, thematic analysis was conducted by coding the data based on the four dimensions (i.e., safety, usage, facilities, and aesthetics) analysed in the quantitative approach. For instance, the relevant text of an interview associated with safety was coded as 'safety'. The same text related to more than one theme was coded more than once. A coding report for each theme was subsequently generated. By relating the interview results with the four dimensions as resulting from the quantitative analysis, the interview results shed light on explaining the associations between environmental qualities and perceived restorativeness. Pseudonyms were used to protect the interviewees' confidentiality.

\section{Results}

\subsection{Behavioural Observations}

Figure 4 shows the frequency of activities in the two cemeteries by using a bar chart. In the Warriston Cemetery, dog walking $(n=42,46.67 \%)$ was the most popular use (Figure 5), followed by walking as a through route $(n=20,22.22 \%)$, sitting down on a bench $(n=13,14.44 \%)$, and others $(n=11,12.22 \%)$. In the Morningside Cemetery, walking as a through route $(n=74,77.89 \%)$ was the most popular use, followed by walking with a baby in a pram $(n=7,7.37 \%)$ (Figure 6$)$, sitting down on a bench $(n=4,4.21 \%)$, and others $(n=4,4.21 \%)$. On average, walking as a through route was the most popular use $(n=94,50.81 \%)$ in the two cemeteries. 


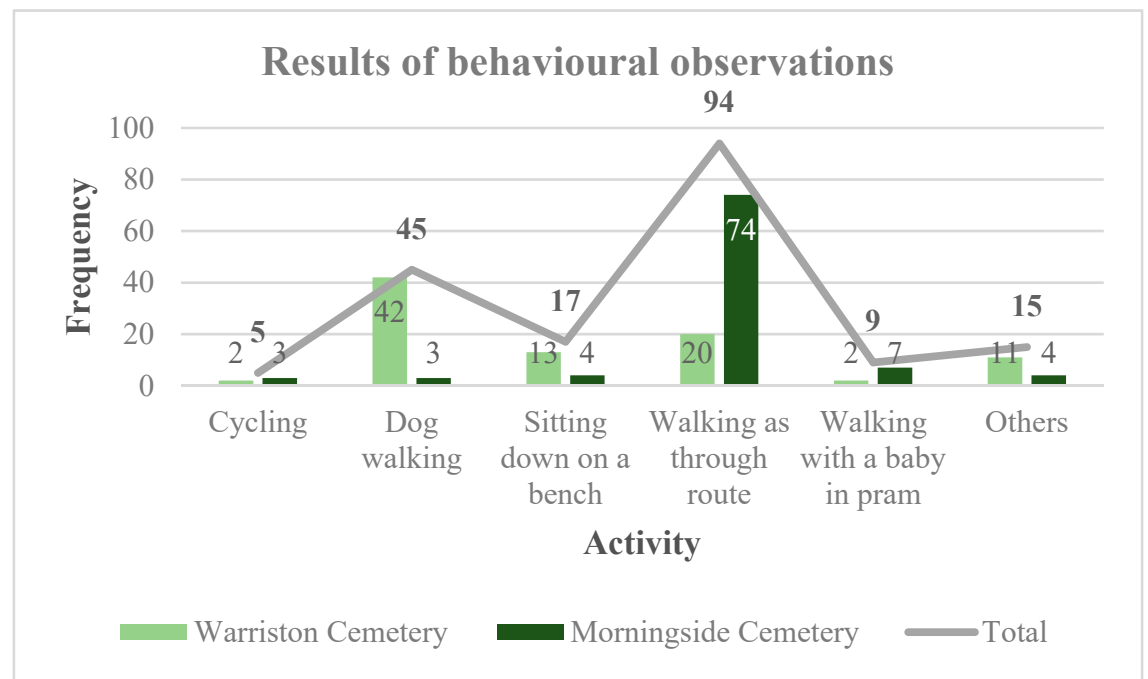

Figure 4. Results of behavioural observations. 'Others' include doing voluntary work, meditation, cycling, running, taking photographs, watching birds, and flying drones.

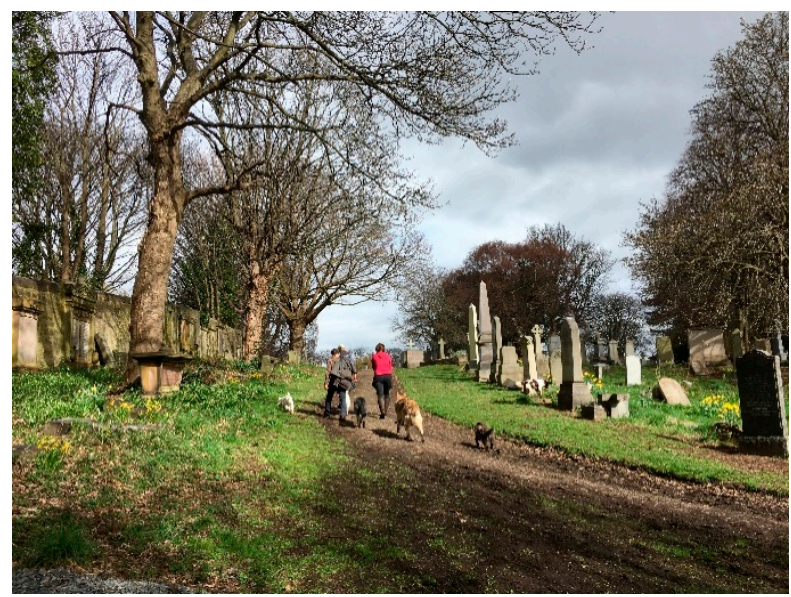

Figure 5. Dog walking at the Warriston Cemetery.

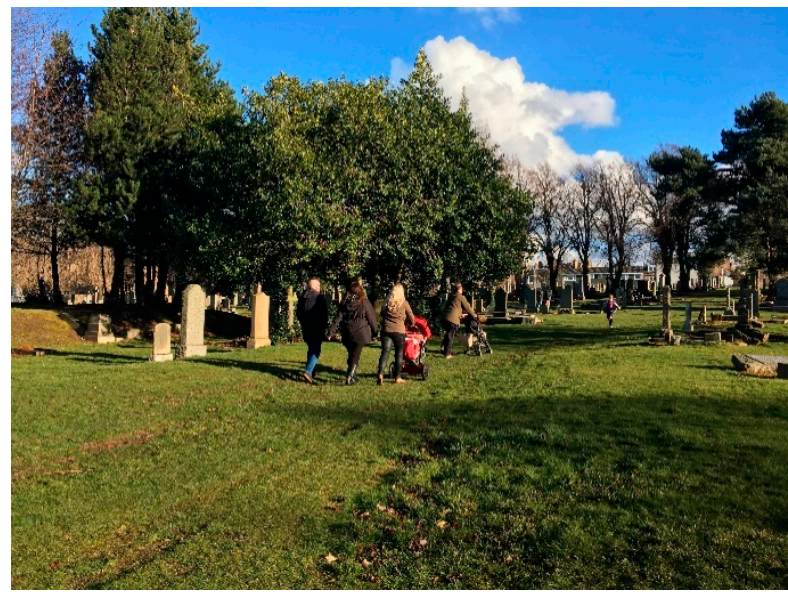

Figure 6. Walking with babies in prams at the Morningside Cemetery.

\subsection{Interviewer-Administered On-Site Survey}

A total of 134 (Warriston: $n=65$; Morningside: $n=69$ ) out of 185 (Warriston: $n=90$; Morningside: $n=95$ ) approached users completed the questionnaires in the two study sites. The response rate of the survey is $72.43 \%$. 
Table 1 shows the results of the descriptive analysis for the sample. Interviewees' mean age was 49.79 (SD = 17.16), and over half of them were female. The participants were mostly married, had an undergraduate degree or above, and were employed or self-employed. The majority also had no physical disability.

Table 1. Descriptive analysis for the sample $(N=134)$.

\begin{tabular}{lcc}
\hline & N/M & $\% / S D$ \\
\hline Study site & & \\
Warriston Cemetery & 65 & $48.5 \%$ \\
Morningside Cemetery & 69 & $51.5 \%$ \\
Sociodemographic characteristics & & \\
Age (years) & 49.79 & 17.16 \\
Male & 60 & $44.8 \%$ \\
Marital status & & \\
Single & 47 & $35.1 \%$ \\
Married & 60 & $44.8 \%$ \\
Cohabitated & 9 & $6.7 \%$ \\
Divorced/separated/widowed & 18 & $13.4 \%$ \\
Education level & & \\
Secondary school or below & 23 & $17.2 \%$ \\
Technical school or similar level & 23 & $17.2 \%$ \\
Undergraduate degree & 49 & $36.6 \%$ \\
Postgraduate degree & 39 & $29.1 \%$ \\
Working status & & \\
Employed/self-employed & 78 & $58.2 \%$ \\
Unemployed & 20 & $14.9 \%$ \\
Retired/partially retired & 36 & $26.9 \%$ \\
Without physical disability & 131 & $97.8 \%$ \\
\hline
\end{tabular}

Note. N, Number; M, Mean; SD, Standard deviation.

Table 2 shows the bivariate correlations between environmental qualities and perceived restorativeness (the 16-item PRS scale and the four dimensions of perceived restorativeness). Both usage and aesthetics were found to be positively correlated with the 16-item PRS scale, being away, compatibility, and fascination. The dimension of facilities was positively correlated with the 16-item PRS scale and compatibility.

Table 2. Bivariate analysis between perceived restorativeness and environmental qualities $(N=134)$.

\begin{tabular}{cccccc}
\hline Variable & M (SD) & Safety & Usage & Facilities & Aesthetics \\
\hline 16-item PRS scale (0-6) & $4.03(1.03)$ & 0.063 & $0.569^{* *}$ & $0.188^{*}$ & $0.370^{* *}$ \\
Being away (0-6) & $3.97(1.72)$ & 0.025 & $0.458^{* *}$ & 0.063 & $0.318^{* *}$ \\
Compatibility (0-6) & $3.57(1.49)$ & 0.114 & $0.557^{* *}$ & $0.214^{*}$ & $0.358^{* *}$ \\
Fascination (0-6) & $3.86(1.46)$ & 0.069 & $0.571^{* *}$ & 0.150 & $0.291^{* *}$ \\
Coherence (0-6) & $4.83(.98)$ & -0.102 & -0.129 & 0.052 & 0.057 \\
\hline Note $* p<0.05 * * *<0.01 \cdot \mathrm{M}(\mathrm{SD})$, Mean (Standard deviation); PRS, Perceived Restorativeness Scale.
\end{tabular}

Table 3 shows the multiple linear regression results for environmental qualities predicting the 16-item PRS scale, being away, compatibility, and fascination. As usage, facilities, and aesthetics were significantly associated with perceived restorativeness in the bivariate analysis, they were further added in the regression analysis. After adjusting for study selections and other sociodemographic characteristics, only usage and aesthetics were significantly and positively associated with the 16-item PRS scale, being away, compatibility, and fascination. All of the models predicting the four outcomes had a $R^{2}$ greater than $38 \%$. Significant results were also shown from the F-tests $(p<0.01)$ across the four models, indicating an acceptable level of model fit. 
Table 3. Summary of multiple linear regression analyses for variables predicting 16-item PRS scale, being away, compatibility, and fascination $(N=134)$.

\begin{tabular}{|c|c|c|c|c|c|c|c|c|c|c|c|c|}
\hline \multirow[b]{2}{*}{ Variable } & \multicolumn{3}{|c|}{ 16-item PRS Scale ${ }^{a}$} & \multicolumn{3}{|c|}{ Being Away ${ }^{a}$} & \multicolumn{3}{|c|}{ Compatibility $^{a}$} & \multicolumn{3}{|c|}{ Fascination $^{a}$} \\
\hline & $B$ & $S E B$ & $\beta$ & $B$ & $S E B$ & $\beta$ & $B$ & $S E B$ & $\beta$ & $B$ & $S E B$ & $\beta$ \\
\hline Usage & 0.630 & 0.111 & $0.419^{* *}$ & 0.766 & 0.208 & $0.305^{* *}$ & 0.898 & 0.166 & $0.413^{* *}$ & 0.837 & 0.158 & $0.393 * *$ \\
\hline Facilities & 0.064 & 0.073 & 0.060 & -0.111 & 0.136 & -0.063 & 0.146 & 0.109 & 0.096 & 0.060 & 0.104 & 0.040 \\
\hline Aesthetics & 0.381 & 0.101 & $0.275^{* *}$ & 0.630 & 0.189 & $0.272^{* *}$ & 0.480 & 0.151 & $0.240^{* *}$ & 0.410 & 0.144 & $0.209^{* *}$ \\
\hline$R^{2}$ & & 0.516 & & & 0.390 & & & 0.478 & & & 0.509 & \\
\hline$F$ & \multicolumn{3}{|c|}{$8.398^{* *}$} & & \multicolumn{2}{|c|}{$5.023^{* *}$} & \multicolumn{3}{|c|}{$7.191^{* *}$} & & \multicolumn{2}{|c|}{$8.160^{* *}$} \\
\hline
\end{tabular}

Note. ${ }^{*} p<0.05 ;{ }^{* *} p<0.01$; adjusted for study site, age, gender, marital status, education level, working status, and physical health. 


\subsection{Face-to-Face On-Site Interviews}

With reference to the factor analysis of environmental qualities in the cemeteries as shown in the survey results, interview results were coded as safety, usage, facilities, and aesthetics. Some representative coding results are shown below to help interpret the survey results in the discussion section. Interviewees' pseudonyms, gender, age, and place of interview are shown in the brackets after each quotation.

\subsubsection{Safety}

As shown from the coding results, some interviewees had experienced or heard of anti-social behaviours in the cemetery, and so gave a poor evaluation with respect to safety. Others had no similar experience, but still had a poor perception of the place in relation to safety. Importantly, a clear difference could be seen in these evaluations on the basis of gender. Participants clearly thought the cemeteries were less safe for women.

'I do know there are drug addicts who lay syringes in the playground, so I imagine they do it here as well, I don't know though. I think it's not safe to walk in any parkland after dark or dark area in the city anywhere in Britain, and I imagine the same in other countries for women in particular.'

(Pauline, female, aged 57, Morningside Cemetery)

Though some interviewees regarded cemeteries as an unsafe place, some walked home using cemetery routes. They found it a peaceful place in the neighbourhood and did not consider safety to be an issue even at night.

'I sometimes walk through here to go home at night. It's a very good neighbourhood, and I don't have any negative associations with this cemetery. I kind of grew up next to a very big park like a cemetery, so it's normal for me. I think this place is very peaceful.'

(Monica, female, aged 25, Warriston Cemetery)

\subsubsection{Usage}

A wide range of physical activities were undertaken in the two cemeteries such as walking, drinking alcohol, cycling, and flying drones. A majority of the interviewees revealed that routes in the Morningside Cemetery were usually taken as a short-cut by residents living nearby to go to the main street for grocery shopping or to return home. In other words, the cemeteries were usually not their final destination but were used as a 'through-space'.

'I am on the way home from the shops. This is a short-cut.'

(Sandy, female, aged 67, Morningside Cemetery)

Interview results commonly showed that pathways in the Warriston Cemetery were often used for dog-walking. Some participants explained that proximity was the main reason for this, while others pointed out that the enclosed space surrounded by high walls allowed them to unleash their dogs. Some dog walkers walked their dogs together if they encountered neighbours.

'In Edinburgh, it's very difficult to find an enclosed area. The parks are all open. Because of the enclosed environment here, I can let my dogs off the leash and they can run around freely.'

(Candy, female, aged 52, Warriston Cemetery)

\subsubsection{Facilities}

Participants' opinions regarding cemetery facilities varied. Some of them regarded the cemeteries as their 'backyard garden' with the desired facilities. For example, some of them sat on the benches and had meetings with friends there. Others however considered facilities as inappropriate, emphasising that cemeteries were a place of tranquillity, unlike a park. 
'It's my backyard garden! I usually sit on the bench drinking beer with my friends on weekends.

I think it is a very nice place, very quiet and peaceful.'

(Betty, female, aged 30, Morningside Cemetery) (Figure 7)

'I don't think if it's necessary to have any facilities in the cemetery. It's a cemetery, not a park.'

(Nina, female, aged 83, Warriston Cemetery)

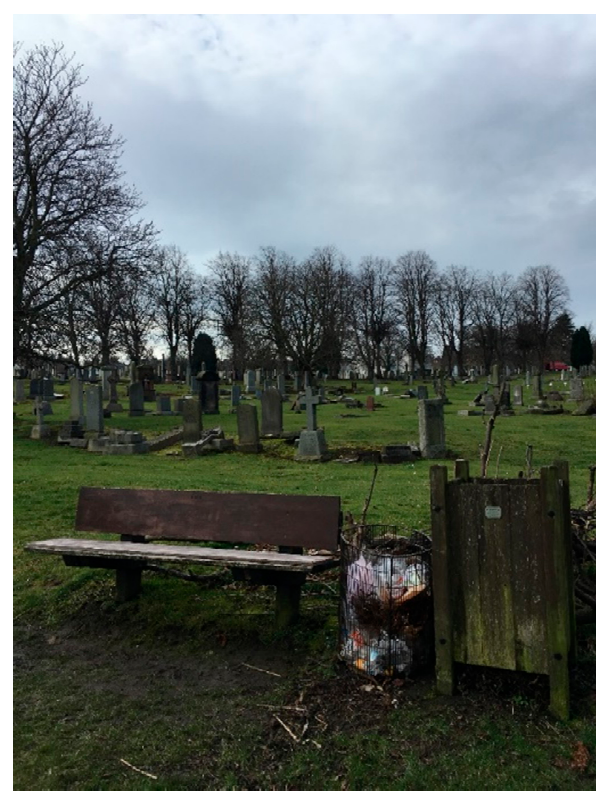

Figure 7. A wooden bench at the Morningside Cemetery.

\subsubsection{Aesthetics}

Some interviewees compared the environment of cemeteries to the streets in their neighbourhood. They appreciated the visual pleasure given by the green setting. In addition to flowers and plants, some of them appreciated the design of the cemetery pathways where they could take exercise.

'When I am walking home, I prefer it, compared to the regular street or other parks. Because it's a little bit more scenic and calm. So I come here five to six times a week. I like the flowers and I like looking at different designs of gravestones, which make this place unique'

(Monica, female, aged 25, Morningside Cemetery)

'I like the curved pathways of this place. It's well designed. As I am recovering from illness, it's good to have some stairs and steep roads where I can do exercise.'

(Kingston, male, aged 42, Warriston Cemetery)

As some interviewees travelled through the cemeteries every day, they found that graveside adornments not only offered aesthetic pleasure, but also implied more meaningful stories and treasured memories.

'I notice there is a grave in the middle which always has lots of flowers. It has been like that for many years ... it's a very young child, so I thought that was very sad... I don't know if I would do the same if it was my child. This is many, many years later and she is still doing it, so that's extraordinary that she is still honouring that memory of her child.'

(Pauline, female, aged 57, Morningside Cemetery) 


\section{Discussion}

We present the first study to investigate the everyday use of the historical urban cemetery in a Scottish context through behavioural observation. This is also an initial study that employed a mixed method approach to explore the associations between environmental qualities of old urban cemeteries and people's perceived restorativeness in contemporary Scotland. The first part of the study reflects on further potential activities and uses of this particular urban space. Findings from the second part are important in identifying the potential for urban cemeteries to affect people's restorative experience.

\subsection{The Everyday Use of Historical Urban Cemeteries}

With the onset of 19th century rapid urban sprawl, many historical cemeteries in the city of Edinburgh (previously situated at the city's edge), were subsumed into new suburban neighbourhoods and subsequently became neighbourhood amenities. This phenomenon subverted how people interacted with this particular environment. Challenging the common perception and expected function of these urban spaces, the two cemeteries in this study were commonly used for the purpose of dog-walking or as an alternative walking route. A study conducted in Norway also found that people often took the trip through the cemetery as an alternative route to work or to other places [18].

The two cemeteries in this study tended to support different activities. The most popular activity in the Warriston Cemetery was dog walking, and in the Morningside Cemetery it was walking as a through route to a different destination. This difference could be caused by the different surrounding environments [13]. For example, a large area of housing exists to the south of Morningside Cemetery with land to the northeast mostly occupied by commercial uses including shops. This spatial relationship could encourage people living nearby to take the cemetery route as a short cut to the grocery store. This appears to be the reason why walking as a through route is the most popular activity in the Morningside Cemetery. However, the Warriston Cemetery, exclusively surrounded by residential land use, (and a lack of nearby public parks with enclosed boundaries) affords people an enclosed green area to allow their dogs to run 'off the leash', making this the most popular activity. The difference in the everyday use of the two cemeteries studied illustrates the flexibility of this land use in relation to people's daily living in the city.

\subsection{Environmental Qualities and Perceived Restorativeness in the Cemeteries}

H1 was supported by our findings. The environmental quality of usage was found to be positively associated with the 16-item PRS scale and three particular dimensions (i.e., being away, compatibility, and fascination) of perceived restorativeness, after controlling for sociodemographic characteristics and site selections. This result indicates that a variety of activities in the cemeteries could be beneficial to different aspects of perceived restorativeness. Unlike other types of greenspace such as parks, cemeteries are usually enclosed spaces surrounded by high walls, which provide a favourable environment for dog walkers to unleash their pets [11]. Compatibility emphasises a positive relationship or good fit between an environment and a person's activities. As the participants' daily activities (e.g., walking as a through route and walking dogs) are afforded by the environment provided in the cemeteries, the level of compatibility is therefore higher. Furthermore, these activities in the cemeteries allow participants to be temporarily apart from the hustle and bustle of the city, thereby enhancing the quality of being away. Fascination indicates a process where one's interests or attention are caught involuntarily $[4,11]$. Activities pursued in the cemeteries spontaneously distracted people from daily demands and stressful thoughts. Directed attention, which usually appears when a demanding cognitive function is required, is therefore minimised, contributing to an increase in effortless attention as well as fascination $[3,4]$.

Another environmental quality, aesthetics, was found to be positively associated with the 16-item PRS scale and three dimensions of perceived restorativeness (i.e., being away, compatibility, and fascination), after controlling for sociodemographic characteristics and site selections. Therefore, H2 was also supported. Similar findings were demonstrated in other studies which emphasised 
the significance of aesthetics in improving perceived restorativeness [40,43]. Though the dimension of aesthetics only contains one item, namely the trees and plants in the cemeteries, the interview results further explained how other aesthetic elements could enhance the restorative potential of these places. As illustrated by the interview results, people appreciated different types of green features in the cemeteries, providing them with an environment distinct and clearly different from more often used places, such as the home and workplace. One participant also emphasised gravestones in the cemeteries as a special feature that further illustrated her sense of being away. More so than other more common types of greenspace such as parks or gardens, many interviewees appreciated the physical design of the cemeteries, highlighting the often curved pathways. Well-designed pathways could also enlarge the visual size of an area [24,44]. Fascinated by natural elements and the ground design, many participants experienced a sense of 'soft fascination' through interacting with these aesthetically pleasing features [3]. Many aesthetic elements of the cemeteries provided visual enjoyment for the participants, thereby increasing their level of fascination. As highlighted by Hartig et al. [4], a higher level of compatibility does not only imply a better match between the environment and human activities, but also a higher degree of interest that generates a reflective cognitive state. One interviewee walking through the cemetery everyday witnessed a woman laying flowers for her deceased child over a very long time. This experience made her reflect deeply and established a person-place bond, enriching her identity of place as well as perception of restorativeness [45,46]. Flowers and other graveside adornments can provide visual enjoyment, but also imply deeper meanings that encourage reflection, potentially heightening the sense of compatibility.

H3 was partially supported. Though presence of facilities was positively correlated with the 16-item PRS scale and compatibility in the bivariate analysis, the relationships were no longer significant in the multiple linear regression analysis. It shows that compared with usage and aesthetics, facilities are less important with respect to restorative potential. As illustrated by the interview results, some participants like to use benches when gathering with friends. The use of benches in the cemeteries shows a match between people's desire to sit down for gathering and what the environment provides. The dimension of facilities was therefore found to be positively correlated with compatibility in the bivariate analysis. However, some participants found it unnecessary to have any facilities in the cemeteries, unlike in public parks where they generally need toilets [47] and playgrounds for children [48]. On the one hand, many participants go to the cemeteries as it is a quiet place, so their reason for visiting the cemetery is relatively simple. Unlike many contemporary cemeteries where toilets and a waiting room are generally provided, these amenities are not typically present in the historical urban cemetery. As facilities in the cemeteries were generally perceived as unnecessary and only a few amenities could be found in the historical urban settings studied here, the dimension of facilities was not significantly associated with the 16-item PRS scale and compatibility in the multiple linear regression analysis.

H4 was not evident. Safety was not significantly correlated with the 16-item PRS scale or any dimension of perceived restorativeness in the bivariate analysis. This result is contradictory to many previous studies. Safety was generally found to enhance various health outcomes at significant levels $[49,50]$. Some scholars indicated that safety could be a very controversial topic [51]. People could have very different experiences in the same cemetery. For example, as some interviewees grew up in a neighbourhood with a greenspace similar to the cemeteries studied here, they did not consider safety an issue in these settings. However, some participants may have a preconceived, negative notion of the cemetery as a potential place of anti-social behaviour such as public alcohol consumption or drug use, resulting in potential bias when evaluating safety. Therefore, people's varied experiences in the cemeteries as well as their attitudes towards them could result in different evaluations of the cemetery as a safe place to visit. Lachowycz and Jones [52] highlighted that cultural and historical attitudes towards greenspace could affect how it is evaluated. The incongruent opinions among the participants made it difficult to establish a solid pattern to explore the relationship between safety and perceived 
restorativeness. Therefore, safety was not significantly correlated with the 16-item PRS scale and any dimension of perceived restorativeness in the bivariate results.

In accordance with a study conducted in the US which found that greenness was not associated with coherence [2], none of the environmental qualities highlighted were found to be related to coherence in this study. Furthermore, in line with other studies [23,27], Cronbach's alpha score of coherence was relatively low here. The result may indicate the incompatibility of some items of coherence with the environment studied. Sufficient coherence demonstrates a sufficient scope for both physical and imagined activities $[23,28]$. In the present study, some people walked their dogs together upon encountering neighbours, illustrating opportunities for physical activities and social encounters more akin to parks [34]. An adequate scope refers to whether or not a place 'provides enough to see, experience, and think about' [24] (p. 173). Proximity to the cemetery provides people with the convenience to walk through it regularly, thus becoming a place people commonly visit as part of their daily routine. Additionally, when people regard the place as a 'backyard garden', they naturally spend more time there and become more familiar with the environment. Freshness and novelty may gradually disappear as a result of everyday use. In other words, for users' who access this place more frequently, it may be harder for the environment to engage their imagination. The limitation of imagined activities may explain the low internal consistency of this dimension and why none of the environmental qualities were correlated with it. How this dimension could be used to explain restorative quality is worthy of further discussion.

\section{Limitations}

This study illustrated the relationships between different environmental qualities and people's perceived restorativeness, but their level of perceived restorativeness could also be impacted by outside factors such as their psychological state prior to their visit to the place of study [53]. Further research which takes more factors into account could be conducted. Some previous studies on greenspace added stressors to participants such as watching a scary movie or doing a paper test before visiting the site. This was not an option for this study due to the decision to focus on users who visit the sites for their own particular reasons. This study also did not conduct comparative research into cemeteries and other greenspace typologies, and this could be a rich seam of investigation. Future research could be conducted to compare how environmental qualities could be correlated with perceived restorativeness or other health outcomes at different times of day or in different seasons. Researchers could also consider quantifying the environmental qualities of cemeteries including the number of tables or benches, and to explore further their relationships with people's health status.

As this is a cross-sectional study, the causal relationship between variables cannot be established. The sample size in the quantitative approach is relatively small, but interviews were conducted to further understand and interpret the survey results in a more comprehensive way. Another limitation considers the potential loss of original data caused by the absence of audio recording. Though the main researcher audio-recorded the discourse on the first few days given the interviewees' consents, it is believed that using field notes without audio recording is more appropriate in the setting of cemeteries. The target group of this study is limited to people who visit the cemeteries quite regularly, and therefore, how less-frequent visitors use and perceive cemeteries could also be addressed. Furthermore, due to the various methods used in this study and limited labour support, some potential interviewees were not approached while the researcher was collecting survey or interview data, potentially leading to less data collection. As cemeteries are still not a particularly well-frequented place this did not occur on many occasions. A few potential users left the study sites when they saw the main researcher at the site entrance, illustrating the potential influence of this study on users' behaviours in the cemeteries. We believe this effect to be minimal. 


\section{Conclusions}

This study presents the everyday use of the historical urban cemetery in a Scottish context, and the positive relationships between environmental qualities and perceived restorativeness in these settings. We believe the study findings may be extended to many historical urban cemeteries in the UK, or other European countries with similar contexts. Functions of a land use are often narrowly defined, ignoring how different types of activity are acted out by the general public. Though interment and remembrance are typically the main human activities that take place in a cemetery, this may no longer be the case for many historical urban cemeteries. This typically occurs where spaces for burial are no longer available and many of the graves, due to their age, may no longer be visited by family members. We here propose two brief recommendations based on our findings. Firstly, in addition to reusing cemeteries for sustainable land use, relevant stakeholders should recognize the daily importance of historical urban cemeteries among dwellers living nearby. In considering the cemetery as a place for people's health benefit, other potential uses and everyday activities could be encouraged or at least tolerated. However, researchers should be aware of potential controversy with respect to the alternative use of cemetery spaces. For example, though usage such as dog walking was found to be positively correlated with perceived restorativeness, some interviewees were of the opinion that it showed a lack of respect. Unlike other types of urban greenspace such as parks and gardens, cemeteries are still a place with special constraints. With the increased variety of everyday use of these spaces, the potential for further facilities such as public toilets also raised concern. Secondly, they should also be aware of the restorative benefits that people can derive from the aesthetical aspects of cemeteries. We believe that the idea of reconsidering urban cemeteries as informal greenspace could significantly influence policy-making, especially in deciding the locations and design of cemeteries. Further research on how these fascinating urban spaces could be utilised should be conducted.

Author Contributions: K.Y.L. collected the data, performed data analysis and prepared the original manuscript. I.S. and Z.S. critically reviewed and edited the manuscript.

Funding: This research received no external funding.

Acknowledgments: The authors would like to thank all the participants for their time spent in this study.

Conflicts of Interest: The authors declare no conflict of interest.

Declarations: The data used in this study is part of the first author's master thesis at the University of Edinburgh.

\section{Appendix A}

Table A1. Factor analysis of the Neighbourhood Open Scale in the cemeteries $(N=134)$.

\begin{tabular}{|c|c|c|c|c|}
\hline & \multicolumn{4}{|c|}{ Component } \\
\hline & 1 & 2 & 3 & 4 \\
\hline & Safety & Usage & Facilities & Aesthetics \\
\hline The paths to the cemetery are safe to walk after dark & 0.796 & & & \\
\hline The cemetery is safe to walk after dark & 0.707 & & & \\
\hline The cemetery is free from crime & 0.681 & & & \\
\hline The paths to the cemetery are easy to walk on & 0.562 & & & \\
\hline The cemetery is good for children to play in & & 0.763 & & \\
\hline The paths to the cemetery are enjoyable to walk through & & 0.710 & & \\
\hline Many different activities take place in the cemetery & & 0.606 & & \\
\hline The cemetery is good for chatting with people & & 0.517 & & \\
\hline There are good facilities in the cemetery & & & 0.903 & \\
\hline Trees and plants in the cemetery are attractive & & & & 0.840 \\
\hline Cronbach's Alpha Score & 0.662 & 0.584 & & \\
\hline$\%$ of Variance explained & 21.15 & 19.32 & 12.28 & 11.03 \\
\hline
\end{tabular}




\section{References}

1. Bowler, D.E.; Buyung-Ali, L.M.; Knight, T.M.; Pullin, A.S. A systematic review of evidence for the added benefits to health of exposure to natural environments. BMC Public Health 2010, 10, 456. [CrossRef]

2. Hipp, J.A.; Gulwadi, G.B.; Alves, S.; Sequeira, S. The Relationship Between Perceived Greenness and Perceived Restorativeness of University Campuses and Student-Reported Quality of Life. Environ. Behav. 2016, 48, 1292-1308. [CrossRef]

3. Kaplan, R.; Kaplan, S. The Experience of Nature: A Psychological Perspective; Cambridge University Press: Cambridge, UK; New York, NY, USA, 1989; Available online: https: //books.google.com.hk/books?hl=en\&lr=\&id=7180AAAAIAAJ\&oi=fnd\&pg=PR7\&ots=TpL3RFpa3k\&sig= AMu2guU28KGiIT70_Pu2GRtmAck\&redir_esc=y\#v=onepage\&q\&f=false (accessed on 10 January 2019).

4. Hartig, T.; Korpela, K.; Evans, G.W.; Gärling, T. A measure of restorative quality in environments. Scand. Hous. Plan. Res. 1997, 14, 175-194. [CrossRef]

5. Bastian, O.; Haase, D.; Grunewald, K. Ecosystem properties, potentials and services-The EPPS conceptual framework and an urban application example. Ecol. Indic. 2012, 21, 7-16. [CrossRef]

6. Næss, P. Residential location affects travel behavior-But how and why? The case of Copenhagen metropolitan area. Prog. Plan. 2005, 63, 167-257. [CrossRef]

7. Rupprecht, C.D.D.; Byrne, J.A.; Ueda, H.; Lo, A.Y. 'It's real, not fake like a park': Residents' perception and use of informal urban green-space in Brisbane, Australia and Sapporo, Japan. Landsc. Urban Plan. 2015, 143, 205-218. [CrossRef]

8. Anderson, E.C.; Minor, E.S. Vacant lots: An underexplored resource for ecological and social benefits in cities. Urban For. Urban Green. 2017, 21, 146-152. [CrossRef]

9. Jackson, J.D.; Smith, J.; Shah, J.P.; Wisniewski, S.J.; Dahm, D.L. Golf after total knee arthroplasty: Do patients return to walking the course? Am. J. Sports Med. 2009, 37, 2201-2204. [CrossRef]

10. Pals, R.; Steg, L.; Siero, F.W.; van Der Zee, K.I. Development of the PRCQ: A measure of perceived restorative characteristics of zoo attractions. J. Environ. Psychol. 2009, 29, 441-449. [CrossRef]

11. Nordh, H.; Evensen, K.H.; Skår, M. A peaceful place in the city-A qualitative study of restorative components of the cemetery. Landsc. Urban Plan. 2017, 167, 108-117. [CrossRef]

12. Brown, T. The making of urban 'healtheries': The transformation of cemeteries and burial grounds in late-Victorian East London. J. Hist. Geogr. 2013, 42, 12-23. [CrossRef]

13. Evensen, K.H.; Nordh, H.; Skaar, M. Everyday use of urban cemeteries: A Norwegian case study. Landsc. Urban Plan. 2017, 159, 76-84. [CrossRef]

14. Harrison, A.R. National Land Use Database: Land Use and Land Cover Classification; version 4.4; Office of the Deputy Prime Minister: London, UK, 2006. Available online: https://assets.publishing.service.gov.uk/ government/uploads/system/uploads/attachment_data/file/11493/144275.pdf (accessed on 8 November 2018).

15. Francis, D. Cemeteries as cultural landscapes. Mortality 2003, 8, 222-227. [CrossRef]

16. Morelli, F.; Mikula, P.; Benedetti, Y.; Bussière, R.; Jerzak, L.; Tryjanowski, P. Escape behaviour of birds in urban parks and cemeteries across Europe: Evidence of behavioural adaptation to human activity. Sci. Total Environ. 2018, 631-632, 803-810. [CrossRef]

17. Indrawati, S.; Soetomo, B.; Setioko, T.W.; Murtini, T.W.; Nurhasan, T.W. Edu-Religious Tourism Based on Islamic Architecture Approach, a Prelimenary Research in Majasto Cemetery-Sukoharjo Regency Central Java. Procedia Soc. Behav. Sci. 2016, 227, 656-663. [CrossRef]

18. Swensen, G.; Nordh, H.; Brendalsmo, J. A green space between life and death-A case study of activities in Gamlebyen Cemetery in Oslo, Norway. Nor. Geogr. Tidsskr. Nor. J. Geogr. 2016, 70, 41-53. [CrossRef]

19. Tângari, V.R. Open Space Systems in Rio de Janeiro: The Public and Private Spheres Reflected in the Urban Landscape. In Urban Public Spaces from Planned Policies to Everyday Politics (Illustrated with Brazilian Case Studies); Capanema Alvares, L., Barbosa, J.L., Eds.; Springer International Publishing: Cham, Switzerland, 2018; pp. 109-126. Available online: https://link.springer.com/book/10.1007\%2F978-3-319-74253-3 (accessed on 9 October 2018).

20. Firth, R. Foreword: The Body in the Sacred Garden. In The Secret Cemetery, English ed.; Doris, F., Kellaher, L., Neophytou, G., Eds.; Berg Publishers: Oxford, UK; New York, NY, USA, 2005; Available online: https: //scholar.google.com/scholar?hl=en\&as_sdt=0,5\&cluster=15010529624822592883 (accessed on 12 May 2018). 
21. Francis, D.; Kellaher, L.; Neophytou, G. Sustaining cemeteries: The user perspective. Mortality 2000, 5, 34-52. [CrossRef]

22. Jones, D. The City of the Dead: The Place of Cultural Identity and Environmental Sustainability in the African-American Cemetery. Landsc. J. Des. Plan. Manag. Land 2011, 30, 226-240. [CrossRef]

23. Marselle, M.R.; Irvine, K.N.; Lorenzo-Arribas, A.; Warber, S.L. Does perceived restorativeness mediate the effects of perceived biodiversity and perceived naturalness on emotional well-being following group walks in nature? J. Environ. Psychol. 2016, 46, 217-232. [CrossRef]

24. Kaplan, S. The restorative benefits of nature: Toward an integrative framework. J. Environ. Psychol. 1995, 15, 169-182. [CrossRef]

25. Kaplan, S. Meditation, Restoration, and the Management of Mental Fatigue. Environ. Behav. 2001, 33, 480-506. [CrossRef]

26. Laumann, K.; Gärling, T.; Stormark, K.M. Rating scale measures of restorative components of environments. J. Environ. Psychol. 2001, 21, 31-44. [CrossRef]

27. Hauru, K.; Lehvävirta, S.; Korpela, K.; Kotze, D.J. Closure of view to the urban matrix has positive effects on perceived restorativeness in urban forests in Helsinki, Finland. Landsc. Urban Plan. 2012, 107, 361-369. [CrossRef]

28. Pals, R.; Steg, L.; Dontje, J.; Siero, F.W.; van Der Zee, K.I. Physical features, coherence and positive outcomes of person-environment interactions: A virtual reality study. J. Environ. Psychol. 2014, 40, 108-116. [CrossRef]

29. Hartig, T.; Mang, M.; Evans, G.W. Restorative Effects of Natural Environment Experiences. Environ. Behav. 1991, 23, 3-26. [CrossRef]

30. World Health Organization. Mental Health Action Plan 2013-2020. Available online: http://apps.who.int/iris/bitstream/handle/10665/89966/9789241506021_eng.pdfjsessionid= 5CF10901D53C2E99BA9F8FF2710E67BA?sequence=1 (accessed on 8 November 2018).

31. Weber, A.M.; Trojan, J. The Restorative Value of the Urban Environment: A Systematic Review of the Existing Literature. Environ. Health Insights 2018, 12. [CrossRef]

32. Ettema, D. Runnable Cities: How Does the Running Environment Influence Perceived Attractiveness, Restorativeness, and Running Frequency? Environ. Behav. 2016, 48, 1127-1147. [CrossRef]

33. Kelly, P.; Williamson, C.; Niven, A.G.; Hunter, R.; Mutrie, N.; Richards, J. Walking on sunshine: Scoping review of the evidence for walking and mental health. Br. J. Sports Med. 2018, 52, 800-806. [CrossRef]

34. Peschardt, K.K.; Stigsdotter, U.K. Associations between park characteristics and perceived restorativeness of small public urban green spaces. Landsc. Urban Plan. 2013, 112, 26-39. [CrossRef]

35. Nikunen, H.; Korpela, K. The effects of scene contents and focus of light on perceived restorativeness, fear and preference in nightscapes. J. Environ. Plan. Manag. 2012, 55, 453-468. [CrossRef]

36. Lo, A.Y.H.; Jim, C.Y. Differential community effects on perception and use of urban greenspaces. Cities 2010, 27, 430-442. [CrossRef]

37. The City of Edinburgh Council. Edinburgh's Population. Available online: http://www.edinburgh.gov.uk/ info/20247/edinburgh_by_numbers/34/edinburghs_population (accessed on 8 November 2018).

38. The City of Edinburgh Council. Cemeteries and Crematoria. Available online: http://www.edinburgh.gov. uk/directory/40/cemeteries_and_crematoria?page=1 (accessed on 8 November 2018).

39. Sugiyama, T.; Thompson, C.W.; Alves, S. Associations Between Neighborhood Open Space Attributes and Quality of Life for Older People in Britain. Environ. Behav. 2009, 41, 3-21. [CrossRef]

40. Tenngart Ivarsson, C.; Hagerhall, C.M. The perceived restorativeness of gardens-Assessing the restorativeness of a mixed built and natural scene type. Urban For. Urban Green. 2008, 7, 107-118. [CrossRef]

41. Veselinova, C. Understanding physical disability. Nurs. Resid. Care 2013, 15, 161-164. [CrossRef]

42. Francis, D.; Kellaher, L.; Neophytou, G. The Secret Cemetery; Berg Publishers: Oxford, UK; New York, NY, USA, 2005; Available online: https://scholar.google.com/scholar?hl=en\&as_sdt=0,5\&cluster= 15010529624822592883 (accessed on 2 May 2018).

43. Nordh, H.; Hartig, T.; Hagerhall, C.M.; Fry, G. Components of small urban parks that predict the possibility for restoration. Urban For. Urban Green. 2009, 8, 225-235. [CrossRef]

44. Herzog, T.R.; Bryce, A.G. Mystery and Preference in Within-Forest Settings. Environ. Behav. 2007, 39, 779-796. [CrossRef] 
45. Bornioli, A.; Parkhurst, G.; Morgan, P.L. The psychological wellbeing benefits of place engagement during walking in urban environments: A qualitative photo-elicitation study. Health Place 2018, 53, 228-236. [CrossRef]

46. Menatti, L.; Subiza-Pérez, M.; Villalpando-Flores, A.; Vozmediano, L.; San Juan, C. Place attachment and identification as predictors of expected landscape restorativeness. J. Environ. Psychol. 2019, 63, 36-43. [CrossRef]

47. Sugiyama, T.; Ward Thompson, C. Associations between characteristics of neighbourhood open space and older people's walking. Urban For. Urban Green. 2008, 7, 41-51. [CrossRef]

48. Fan, M.; Jin, Y. Do Neighborhood Parks and Playgrounds Reduce Childhood Obesity? Am. J. Agric. Econ. 2014, 96, 26-42. [CrossRef]

49. Nijs, M.; Bun, C.; Tempelaar, W.; Wit, N.; Burger, H.; Plevier, C.; Boks, M. Perceived School Safety is Strongly Associated with Adolescent Mental Health Problems. Community Ment. Health J. 2014, 50, 127-134. [CrossRef]

50. Van Dyck, D.; Teychenne, M.; McNaughton, S.A.; De Bourdeaudhuij, I.; Salmon, J. Relationship of the perceived social and physical environment with mental health-related quality of life in middle-aged and older adults: Mediating effects of physical activity. PLoS ONE 2015, 10. [CrossRef]

51. Madge, C. Public parks and the geography of fear. Tijdschr. Voor Econ. En Soc. Geogr. 1997, 88, $237-250$. [CrossRef]

52. Lachowycz, K.; Jones, A. Does walking explain associations between access to greenspace and lower mortality? Soc. Sci. Med. 2014, 107, 9-17. [CrossRef]

53. Stevens, P. Affective priming of perceived environmental restorativeness. Int. J. Psychol. 2014, 49, 51-55. [CrossRef]

(C) 2019 by the authors. Licensee MDPI, Basel, Switzerland. This article is an open access article distributed under the terms and conditions of the Creative Commons Attribution (CC BY) license (http://creativecommons.org/licenses/by/4.0/). 